Thorax, 1979, 34, 187-193

\title{
Effective time of the forced expiratory spirogram in health and airways obstruction
}

\author{
J JORDANOGLOU, E KOURSOUBA, C LALENIS, T GOTSIS, J KONTOS, AND \\ C GARDIKAS
}

From the Professorial Medical Unit, Evangelismos Hospital, Athens, Greece

ABSTRACT We have calculated the effective time ( $t$ eff) of the forced expiratory spirogram in healthy non-smokers, in patients with simple chronic bronchitis, and in patients with chronic obstructive lung disease. Effective time was obtained by dividing the area underneath the forced expiratory spirogram by the forced vital capacity (FVC) and is equal to the time constant of lung emptying if the FVC-time curve is a single exponential. In 75 healthy non-smoking adults, $t$ eff showed a linear increase with age but no difference between the sexes. In 37 patients with low forced expiratory volume in one second $\left(\mathrm{FEV}_{1}\right) / \mathrm{FVC}$ ratios, $\mathrm{t}$ eff, as expected, was increased. In 19 subjects with simple chronic bronchitis and normal $F_{1} V_{1} / F V C$ ratios, $t$ eff was longer than or at the upper limit of $2 \mathrm{SE}$ above the mean for healthy subjects of the same age. A comparison of $t$ eff with $\mathrm{FEV}_{1} / \mathrm{FVC}$ suggested that in most normal subjects and patients the forced expiratory spirogram was a multiple exponential and that $t$ eff was a more sensitive index for the evaluation of airway obstruction than the $\mathrm{FEV}_{1} / \mathrm{FVC}$ ratio.

The forced expiratory spirogram has been widely used for the assessment of lung function but most of the parameters derived from this curve are dependent on the age, sex, and lung size of the subject. For these reasons several attempts have been made to measure a time factor characteristic of the curve and independent of lung volume. The only commonly used measurement is the ratio of forced expiratory volume in one second $\left(\mathrm{FEV}_{1}\right)$ to forced vital capacity (FVC). More elaborate measurements have been made by Dayman (1961), who described the ratio of change of flow (dV) to change of volume (dV) derived from the maximal flow-volume curve. Fish et al (1974) provided preliminary results on the mean transit time of the forced expiratory spirogram, and this was measured in healthy young subjects aged 9-22 years and in patients with cystic fibrosis by Neuburger et al (1976a and b). These authors claimed that the mean transit time may serve as a single overall measurement of airway function because of its sensitivity to both large and small airways obstruction.

In this paper we describe measurements of the effective time of the forced expiratory spirogram in healthy adults, in patients suffering from simple chronic bronchitis with normal FEV $_{1} / F V C$ ratios, and in patients with chronic obstructive lung disease with low $\mathrm{FEV}_{1} / \mathrm{FVC}$ ratios. The results suggest that effective time, which can be derived by a simple mathematical procedure, is a more sensitive detector of airway disease than the $\mathrm{FEV}_{1} / \mathrm{FVC}$ ratio.

\section{Methods}

The area under any forced expiratory spirogram (FVC-time curve) may be considered as equal to that of a rectangle, the sides of which are the FVC and a segment on the time axis, which we call effective time ( $t$ eff) (fig 1 ),

that is,

and

$$
\int V d t=F V C . t \text { eff }
$$

$$
\mathrm{t} \text { eff }=\int V d t / F V C
$$

Where $\mathrm{V}$ is the volume change at any time $t$ and $\int V d t$ is the area underneath the FVC-t curve. It can be shown mathematically that $t$ eff is equal to the time-constant $(T)$ in single exponential curves (see appendix). Effective time is equivalent to mean transit time.

Forced expiratory spirograms were obtained from three groups of healthy non-smoking subjects:

(a) 75 subjects ( 46 men and 29 women) aged 20-69 years,

(b) 73 subjects ( 44 men and 29 women) aged 23-72 years, and 


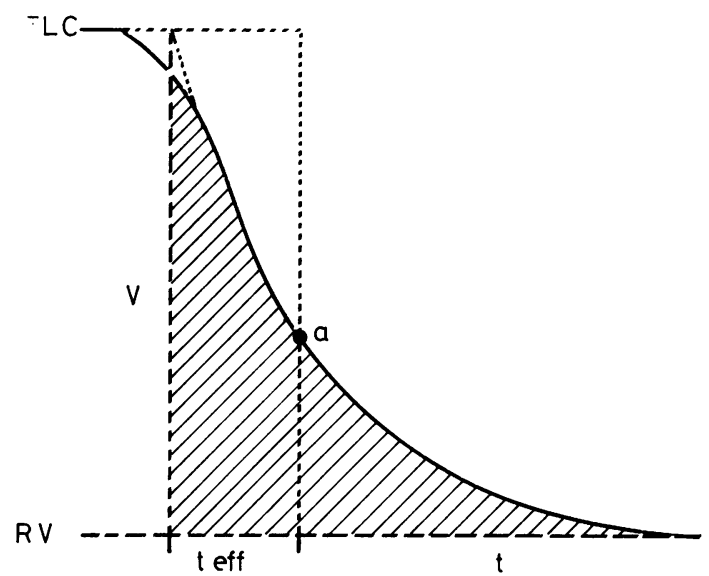

Fig 1 Diagram showing a forced expiratory spirogram. Change in volume $(V)$ between total lung capacity $(T L C)$ and residual volume $(R V)$ is plotted against time to give forced vital capacity-time (FVC-t) curve. Origin of curve is found by extrapolation of fast phase of curve towards horizontal TLC level. Striped area underneath spirogram represents integral $\int V d t$. This area is equal to area of a rectangle, the sides of which are FVC and effective time ( $t$ eff ). If FVC-t curve is a single exponential $t$ eff corresponds to $0.63 \times F V C$ (point a).

(c) 17 men aged 24 years with a height range $1 \cdot 61-1.85 \mathrm{~m}$.

In none of these subjects was there a history of lung, thoracic wall, or heart disease; examination showed no abnormalities and the chest radiographs were normal. The values for $\mathrm{FEV}_{1}, \mathrm{FVC}$, and $\mathrm{FEV}_{1} /$ FVC were within normal limits $( \pm 1$ SD predicted by the nomograms of Cotes (1968)). We also studied 56 male patients, who were divided into two groups:

(d) 37 patients aged 20-75 years suffering from chronic obstructive lung disease with an $\mathrm{FEV}_{1} / \mathrm{FVC}$ ratio more than $7 \%$ below the predicted value, and

(e) 19 patients aged 25-75 years who were heavy cigarette smokers (20-25 cigarettes daily for more than five years) and who suffered from simple chronic bronchitis, that is, chronic cough and expectoration with a normal $\mathrm{FEV}_{1} / \mathrm{FVC}$ ratio for their age. In this group of patients the $\mathrm{FEV}_{1} / \mathrm{FVC}$ ratio differed from the predicted normal ratio by $+2 \%$ to $-7 \%$.

Measurements were made with the subject in the sitting position and breathing through a mouthpiece (id $2.55 \mathrm{~cm}$ ) that was connected with the cone of a heated Fleisch pneumotachograph screen type 4. After a deep breath up to the total lung capacity (TLC), the subject performed a forced expiratory manoeuvre to residual volume (RV). The subject's maximum effort was maintained until no further gas could be expired. The screen was connected with a
Statham PM 15 transducer, the signal from which $\stackrel{\overrightarrow{\vec{S}}}{\stackrel{\vec{f}}{+}}$ was amplified by a Hewlett-Packard $1100 \mathrm{C}$ pre- $\frac{\mathrm{C}}{\mathrm{C}}$ amplifier. FVC-t curves were obtained by integration $\frac{\bar{\sigma}}{\overline{0}}$ of flow by a Hewlett-Packard $3700 \mathrm{~A}$ integrating $\frac{\mathrm{m}}{\sigma}$ preamplifier and were recorded on a 7700 pen- $\stackrel{\Phi}{\Omega}$ recorder. The speed of the paper was $25 \mathrm{~mm} / \mathrm{s}$. The system (screen-transducer-amplifiers) was calibrated $\vec{\circ}$ by the use of a rotameter at a constant flow of 200. $1 / \mathrm{min}$. The system had a linear response at flows up to $\vec{\omega}$ $6001 / \mathrm{min}$. In four normal subjects in whom the peak expiratory flow was between 600 and $7001 / \mathrm{min}$ a $\vec{x}$ calibration curve for volume was constructed. The $\underset{\perp}{\omega}$ origin of the FVC-t curve, when necessary, was is determined by extrapolation of the fast phase of the $\vec{\infty}$ curve (Smith and Gaensler, 1975) (fig 1). The area of the FVC-t curve was computed by the use of a $\frac{\text { o }}{2}$ program written on a magnetic card and inserted in $\rightarrow$ the 65 Hewlett-Packard electronic calculator. The $\frac{7}{0}$ time axis $(\mathrm{t})$ was divided into a number $(\mathrm{n})$ of equal divisions (n was usually 10-12, but was as many as $35 \overrightarrow{\vec{\varphi}}$ in subjects with pronounced curvilinear FVC-t curves). Volume above $\mathrm{RV}\left(\mathrm{V}^{\prime}\right)$ was sampled at these 0 times and a rectangular approximation made by assuming $\mathrm{V}^{\prime}$ was unchanged during the time interval $(t / n)$. The area $\int V d t$ was then calculated from the equation

$$
\int \mathrm{Vdt}=(\mathrm{t} / \mathrm{n})\left[(\mathrm{FVC} / 2)+\left(\Sigma_{1} \mathrm{n}^{-1} \mathrm{~V}^{\prime}\right)\right]
$$

which gave values practically equal to those measured by planimetry (difference less than $2 \%$ ). The sensitivity of the preamplifiers $(1100 \mathrm{C}$ and $3700 \mathrm{~A})$ was such that for every subject the deviation of the pen for the FVC was not less than $25 \mathrm{~mm}$. On the FVC-t curve the $\mathrm{FEV}_{1}$ was also measured. Three or four FVC-t curves were obtained successively in each subject with a time interval between the FVC manoeuvres of 2-3 minutes and the curve with the maximum value for FVC was used for analysis. If two or more curves with the same FVC values showed different values of $t$ eff, the curve with the minimum $t$ eff was selected.

\section{Results}

Effective time ( $t$ eff) increased with age in 75 healthy subjects (group A) between 20 and 69 years (fig 2). Age and $t$ eff were related to each other by the linear regression equation

$$
t \text { eff (secs) }=0.1573+0.0141 \times \text { age (years) }
$$

For comparison the results for the mean transit time in normal children obtained by Neuburger et al 0 (1976a) are also plotted in fig 2. There was a weak $\underset{\mathbb{D}}{\mathbb{D}}$ inverse relation between t eff and FVC in 73 normal $\overrightarrow{\mathbb{D}}$ subjects (44 men, 29 women) aged 23-72 years (group B) and at a given FVC, $t$ eff tended to be shorter in women than in men (fig 3). In 17 normal 8 men of the same age ( 24 years), but with different 


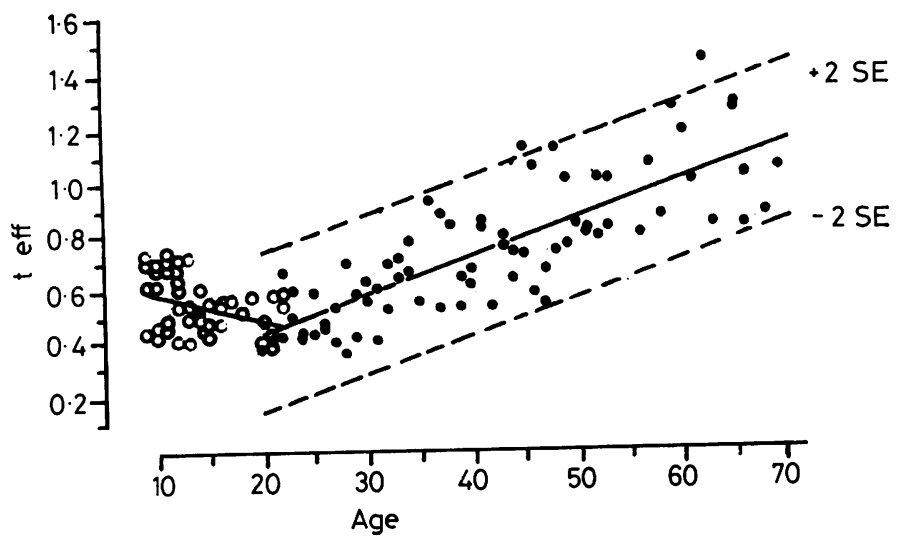

Fig $2-=$ Relationship between effective time ( $t$ eff) (in seconds) and age (in years) in 75 normal subjects. - represents mean value for $t$ eff at considered age while ----correspond to $\pm 2 S E$. Age and t eff were related to each other by linear regression equation: $t$ eff $(s)=0 \cdot 1573+$ $0.0141 \times$ age $($ years $)\left(r^{2}=0.6255\right.$; paired $t$ test, $0.0005<\mathrm{P}<0.0025)$. $\bigcirc$ represent data of Neuburger et al (1976a) for mean transit time in children and young adults.

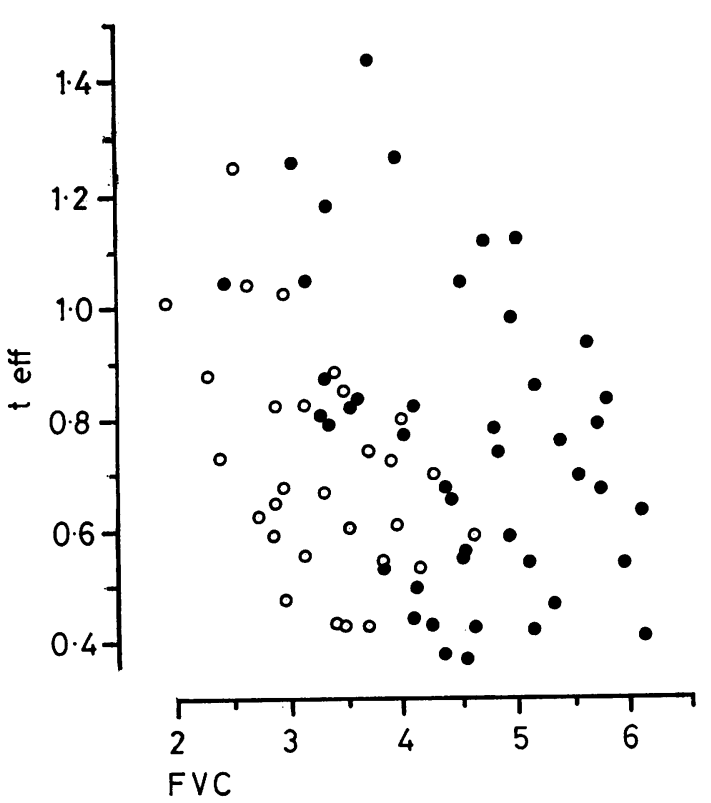

Fig 3 Relation of effective time ( $t$ eff) (in seconds) to forced vital capacity (FVC) (in litres) in 73 normal subjects of various ages. represent men and $\bigcirc$ women. Statistical analysis of results shows that $t$ eff is related to FVC according to linear regression equations

$$
\begin{aligned}
& t \text { eff }(\mathrm{sec})=1.2921-0.1173 \times F V C(l) \text { (men) } \\
& t \text { eff }(\mathrm{sec})=1.1443-0.1332 \times F V C(l) \text { (women) }
\end{aligned}
$$

In these equations: $r^{2}=0.1572$ (men) and $r^{2}=0.1812$ (women); paired t test, $0.01>\mathrm{P}>0.005$.

heights (range 1.61-1.85 m) (group C), however, t eff showed very little relation to the FVC (fig 4). The values of $t$ eff in relation to age were increased in patients suffering from chronic obstructive lung disease (group D) and also in patients with simple chronic bronchitis (group E) (fig 5). The relation of $t$

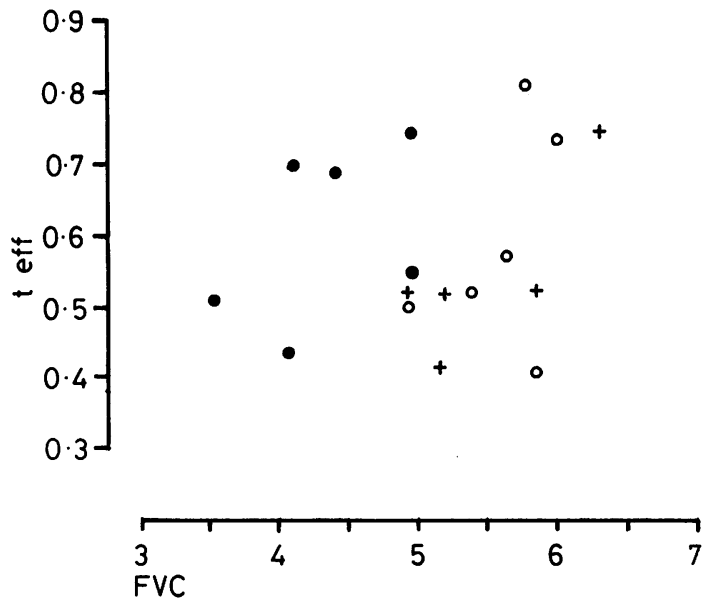

Fig 4 Relation of effective time ( $t$ eff) (in seconds) to forced vital capacity $(F V C)(l)$ in 17 normal men (group $C$ ), all 24 years old but with a height range $1.61-1.85 \mathrm{~m}$.

correspond to six subjects with a height of 1.61-1.66 m, $\bigcirc$ to six subjects with a height of 1.80-1.85 $\mathrm{m}$, and + to five subjects with a height of $1.67-1.79 \mathrm{~m}$.

eff to the $\mathrm{FEV}_{1} / \mathrm{FVC}$ ratio in these 56 patients is shown in fig 6 together with results for 75 normal subjects (group A).

The ideal relationship between $t$ eff and $F_{E V} / F V C$ ratio in single exponential FVC-t curves is given by the equation

$$
\mathrm{FEV}_{1} / \mathrm{FVC}=1-\mathrm{e}^{-1 / \mathrm{t}} \text { eff }
$$

It can be seen that in the great majority of subjects $t$ eff was longer than the ideal value at a given $F_{E V}$ / FVC ratio. The 131 subjects in fig 6 were divided into eight groups according to the value of $\mathrm{FEV}_{1} /$ FVC. In each group the coefficient of variation of $t$ eff was greater than for $\mathrm{FEV}_{1} / \mathrm{FVC}$ (see table). 


\section{Discussion}

The mean transit time of the forced expiratory spirogram (FVC-t curve) has recently been introduced as a sensitive test suitable for the early detection of airway narrowing (Fish et al, 1974; Neuburger et al, 1976a,b). Mean transit time is a statistical parameter, the first moment of the curve, which is equal to the area under the FVC-t curve divided by the FVC (Neuburger et al, 1976a). The ratiofVdt/ FVC is a time characteristic of the FVC-t curve that we have called effective time ( $t$ eff). Our results show that $t$ eff rises through adult life in normal subjects (fig 2). Combining our data for adults with the results of Neuburger et al (1976a) for mean transit time in normal children of nine years or older it appears that the minimum values of $t$ eff correspond to about the age of 22 years. Considering that $t$ eff of any volume-time curve is the product of the effective values of compliance and resistance (Jordanoglou et al, 1978), it seems that at this age the chest has its lowest value of effective resistance and compliance. This agrees with previous findings that at about this age the volume-pressure curve of the lung is supposed to go through its highest values of the lung recoil pressures and closing volume (as a percentage of vital capacity) goes through a minimum value (Mansell et al, 1972). The dispersion of the values for $t$ eff round the mean is greater beyond the age of 35 years than in the younger subjects, and this poses the question of how strict the criteria must be for the selection of normal subjects in the older age groups.

The relation of $t$ eff to lung size is less clear. According to our data, FVC is inversely related to $t$ eff, and the relation is slightly different in the two sexes. There was no appreciable difference (less than $0.01 \mathrm{sec}$ in any age group), however, in $t$ eff between men and women. The overlapping of long $t$ eff in men with short $t$ eff in women at any given FVC, below about 4.51 , may be explained by the slope of the regression lines (see equations in the legend of

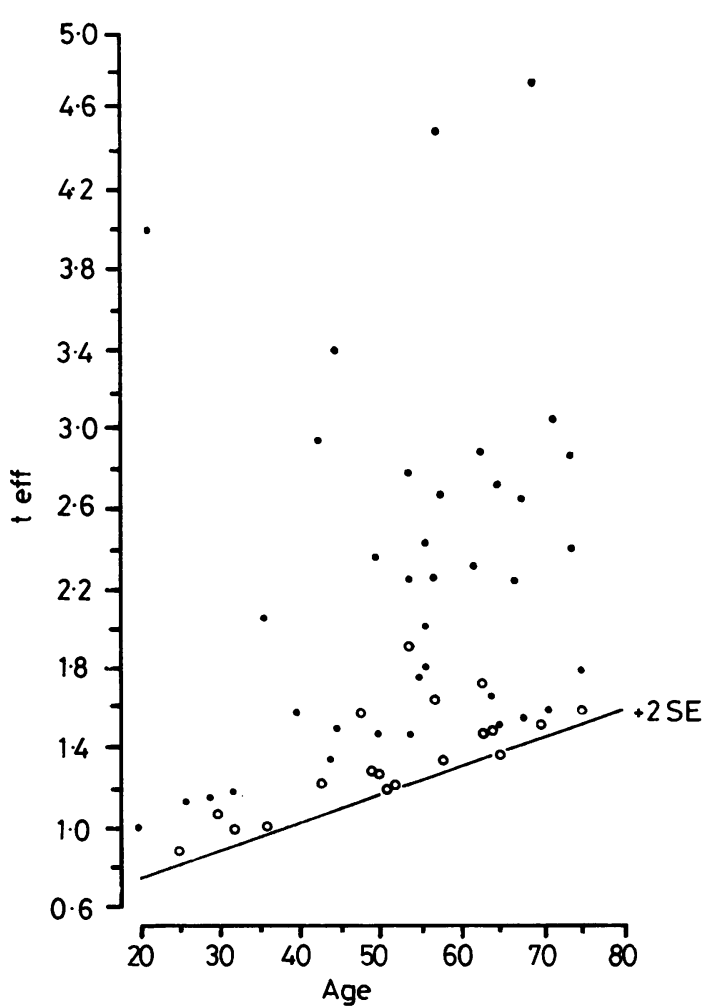

Fig $5 \quad-=$ Relation of effective time ( $t$ eff) (in seconds) to age (years) in 37 men suffering from chronic obstructive lung disease with reduced FEV $1 / F V C$ ratio (group $D$ ). $O$ show $t$ eff in relation to age obtained from 19 subjects suffering from chronic cough and expectoration with a normal FEV $1 / F V C$ ratio (group $E$ ). - - represents $+t$ two SE line for healthy subjects of fig 2.

fig 3). Furthermore, the points in fig 3 correspond to subjects of both sexes with different age and height. In order to study the effect of the height (and consequently lung volume) on $t$ eff we studied a group of 17 normal non-smoking men (group C), who were all

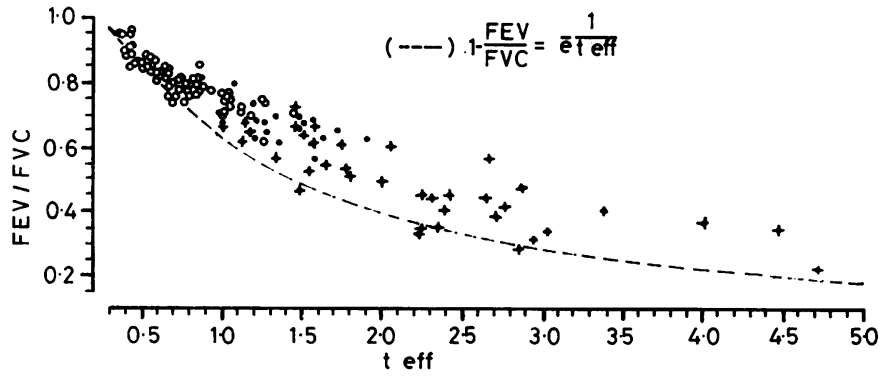

Fig 6 Relationship between FEV 1 FVC ratio (as a fraction of unity) and effective time ( $t$ eff) (in seconds) in all 131 subjects studied: $\bigcirc=$ normal subjects, $+=$ patients with reduced $F E V_{1} / F V C$ (group $\left.D\right)$, and $=$ patients with normal FEV $1 / F V C$ (group C). ---- represents ideal relationship between $t$ eff and $F E V_{1} / F V C$ according to equation (5) (see text). 
Relation between mean value of $F E V_{1} / F V C$ and mean effective time ( $t$ eff) in groups divided according to value of $F E V_{1} / F V C$

\begin{tabular}{|c|c|c|c|c|c|}
\hline \multirow[t]{2}{*}{$F E V_{1} / F V C$ groups } & $F E V_{1} / F V C$ & $F E V_{1} / F V C$ & $t$ eff & $t$ eff & $C V(t$ eff $)$ \\
\hline & Mean & $\pm S D$ & Mean $(s)$ & $\pm S D(s)$ & $C V\left(F E V_{1} / F V C\right)$ \\
\hline $\begin{array}{l}0.90-0.962(n=7) \\
0.80-0.899(n=37) \\
0.70-0.799(n=37) \\
0.60-0.699(n=23) \\
0.50-0.599(n=8) \\
0.40-0.499(n=9) \\
0.30-0.399(n=8) \\
0.23-0.299 *(n=2)\end{array}$ & $\begin{array}{l}0.9336 \\
0.8393 \\
0.7528 \\
0.6519 \\
0.5420 \\
0.4466 \\
0.3539 \\
-\end{array}$ & $\begin{array}{l}0.0238 \\
0.0295 \\
0.0310 \\
0.0258 \\
0.0267 \\
0.0261 \\
0.0220 \\
-\end{array}$ & $\begin{array}{l}0.4134 \\
0.6402 \\
0.9835 \\
1 \cdot 4255 \\
1 \cdot 7938 \\
2 \cdot 5028 \\
2 \cdot 9963 \\
-\end{array}$ & $\begin{array}{l}0 \cdot 0273 \\
0 \cdot 1444 \\
0 \cdot 2251 \\
0 \cdot 2765 \\
0 \cdot 4017 \\
0 \cdot 5178 \\
0 \cdot 8317 \\
-\quad\end{array}$ & $\begin{array}{l}2 \cdot 59 \\
6 \cdot 43 \\
5 \cdot 56 \\
4 \cdot 90 \\
4 \cdot 54 \\
3 \cdot 54 \\
4 \cdot 46 \\
-\quad\end{array}$ \\
\hline
\end{tabular}

SD $=$ Standard deviation.

$\mathrm{n}=$ Number of subjects in each $\mathrm{FEV}_{1} / \mathrm{FVC}$ group.

*Only two subjects, so parameters not calculated.

$\mathrm{CV}=$ Coefficient of variation ( $=\mathrm{SD} /$ mean).

$\mathrm{FEV}_{1} / \mathrm{FVC}$ expressed as a fraction of unity.

aged 24 but with different heights (fig 4). There was no relation between $t$ eff and FVC; this finding is in contradiction to the data of Neuburger et al (1976a), in which mean transit time was directly related to the FVC.

The rate of change in lung volume during forced expiration has also been assessed from the slope of the maximum expiratory flow-volume curve $(\Delta \mathrm{V} / \Delta \dot{\mathrm{V}})$, which is an index related to the product of compliance and resistance (Mead et al, 1967; Cotes, 1968; Jordanoglou and Pride, 1968a; Sykes et al, 1969; Agostoni, 1970; Dennis and Douglas, 1970; Yamabayashi et al, 1970; Bates et al, 1971; Gelb et al, 1973; Knudson et al, 1973). Dayman (1961) in maximal expiratory flow-volume curves reported a mean value of 0.37 seconds for $\mathrm{dV} / \mathrm{dV}$. Takishima et al (1967) reported values between 0.3 and $0.7 \mathrm{~s}$ for the $\Delta \mathrm{V} / \Delta \dot{\mathrm{V}}$ slope in normal maximal expiratory flowvolume curves, while Jordanoglou and Pride (1968b) found that the value of $\Delta \mathrm{V} / \Delta \dot{V}$ over the range between $40 \%$ and $60 \%$ of the FVC in normal subjects was about $0.42 \mathrm{~s}$. The $\Delta \mathrm{V} / \Delta \dot{\mathrm{V}}$ slope of the maximal expiratory flow-volume curve is a parameter with dimensions of time, but will vary over the course of a forced expiration unless the FVC-time curve follows a single exponential. When there is airways obstruction the values of $\Delta \mathrm{V} / \Delta \dot{\mathrm{V}}$ characteristically increase as expiration continues (Takishima et al, 1967; Jordanoglou and Pride, 1968b) so that it is not possible to describe adequately such curves by a single value for the slope.

Lung emptying during forced expiration can also be assessed by the $\mathrm{FEV}_{1} / \mathrm{FVC}$ ratio, which is considered by British authors to be the most satisfactory parameter for the detection of airways obstruction (Medical Research Council, 1965; Sartorelli, 1966; National Heart and Lung Institute, 1974). Normal values of $F E V_{1} / F V C$ mainly depend on age, rather than on sex, lung volume, or height (Berglund et al,
1963) and so it was thought that it would be useful to study the relation of $t$ eff to the $\mathrm{FEV}_{1} / \mathrm{FVC}$ ratio. The effective time in all the patients with chronic obstructive lung disease with low $\mathrm{FEV}_{1} / \mathrm{FVC}$ ratios was considerably longer than in normal subjects of the same age, and was at or above the upper limit of normal in patients with chronic cough and expectoration in whom the $\mathrm{FEV}_{1} / \mathrm{FVC}$ ratio was normal or only slightly below the mean predicted value (fig 5). It is possible to construct an ideal relationship between effective time and the $\mathrm{FEV}_{1} / \mathrm{FVC}$ ratio, because the $\mathrm{FEV}_{1} / \mathrm{FVC}$ ratio is equal to $\left(1-\mathrm{e}^{-1 / \mathrm{t}}\right.$ eff $)$ in single exponential FVC- $t$ curves. In this case the timeconstant $(T)$ of the curve and the effective time ( $t$ eff) have the same value (see appendix). The minimum value of $t$ eff at any $F E V_{1} / F V C$ level cannot be shorter than that determined by the ideal curve, corresponding to a single exponential FVC-t curve. In multiple exponential FVC-t curves, however, the $\mathrm{FEV}_{1} / \mathrm{FVC}$ ratios are expected to have higher values at any given $t$ eff than that determined by the ideal curve. This is because the major part of the expired air in the first second is expelled from the fast emptying region of the lungs, resulting in high $\mathrm{FEV}_{1} / \mathrm{FVC}$ ratios, whereas $t$ eff reflects the rate of emptying throughout expiration. In most of the subjects studied the points deviate from the ideal curve (fig 6) especially with $\mathrm{FEV}_{1} / \mathrm{FVC}$ ratios below $0 \cdot 85$. This was found in both normal subjects and patients and suggests that in these cases the FVC-t curve is a multiple exponential. This finding agrees with the studies of Takishima et al (1967), who claimed that there are time-constant discrepancies within the lungs of normal subjects and patients. Consequently, the term "time-constant" of the respiratory system cannot be generally used unless the FVC-t curve is a single exponential. Lowell and Schiller (1953) showed that in a limited number of subjects the FVC-t curve was represented by a nearly straight line 
on a semi-log paper, indicating that these curves were a single exponential but this was true only of a minority of our subjects.

The theoretical considerations above suggest that $t$ eff may be expected to be a more sensitive means for detecting airway obstruction than the $\mathrm{FEV}_{1} / \mathrm{FVC}$ ratio, as it is accepted that the earliest changes in maximum expiratory flow are towards the end of expiration. This conclusion is supported by the present results which show that the scatter of the points on the $t$ eff axis was wider than those on the $\mathrm{FEV}_{1} / \mathrm{FVC}$ axis (fig 6 and table).

Because $t$ eff reflects events throughout expiration it is also likely to be a more reliable parameter than the forced expired time (time to complete a full forced expiration) which depends heavily on the extent to which an individual sustains the final stages of his expiratory effort. As $t$ eff can be derived rather simply from a forced expiratory spirogram we believe it deserves further study as a sensitive measurement of airflow obstruction.

\section{Appendix}

In a single exponential forced vital capacity versus time curve (FVC-t curve), the time-constant (T), the forced vital capacity (FVC), and the expired volume $\mathrm{V}$ at any time $t$ are related to each other by the equation:

$$
V=F V C \cdot e^{-\frac{t}{T}}
$$

where: $e=2.71828 \ldots \bumpeq 2.72$ base of the natural logarithms. Integrating both sides of equation (6) with respect to time the following equations are obtained:

$$
\begin{aligned}
& \int V d t=F V C \int e^{-T} d t \\
& \int V d t=F V C\left(e^{-\frac{t}{T}} /-\frac{1}{T}\right)_{0}^{\infty} \\
& \int V d t=-F V C . T \cdot\left(e^{-\frac{t}{T}}\right)_{0}^{\infty} \\
& \int V d t=-F V C . T\left(e^{-\infty}-e^{0}\right) \\
& \int V d t=F V C . T \\
& T=\frac{\int V d t}{F V C}
\end{aligned}
$$

It is obvious that according to the equations (2) and (12) $T$ is equal to $t$ eff in single exponential FVC- $t$ curves.

We thank Dr N B Pride for his constructive criticism.

\section{References}

Agostoni, E (1970). Dynamic properties of the relaxed respiratory system. In The Respiratory Muscles, Mechanics and Neural Control, edited by E J M Campbell, E Agostoni, and J Newsom Davis, 2nd edn, $p$ 84. Lloyd-Luke, London.

Bates, D V, Macklem, P T, and Christie, R V (1971). Respiratory Function in Disease, 2nd edn, pp 38-39. W B Saunders Co, Philadelphia.

Berglund, E, Birath, G, Bjure, J, Grimby, G, Kjellmer, I, Sandqvist, L, and Söderholm, B (1963). Spirometric studies in normal subjects. I. Forced expirograms in subjects between 7 and 70 years of age. Acta Medica Scandinavica, 173, 185-192.

Cotes, J E (1968). Lung Function, Assessment and Application in Medicine, 2nd edn, pp 136, 137, 381. Blackwell, Oxford and Edinburgh.

Dayman, H (1961). The expiratory spirogram. American Review of Respiratory Disease, 83, 842-855.

Dennis, M W, and Douglas, J S (1970). Control of bronchomotor tone in spontaneously breathing, unanesthetized guinea pigs. In Airway Dynamics, edited by A Bouhuys, pp 253-262. Thomas, Springfield.

Fish, J, Menkes, H, Rosenthal, R, Summer, W, Norman, P, and Permutt, S (1974). The effect of acute bronchospasm on the distribution of transit times during forced expiration. American Review of Respiratory Disease, 109, 700.

Gelb, A F, Gold, W M, Wright, R R, Bruch, H R, and Nadel, J A (1973). Physiologic diagnosis of subclinical emphysema. American Review of Respiratory Disease, 107, 50-63.

Jordanoglou, J, Kontos, J, and Gardikas, C (1979). Total effective resistance and effective compliance of the lungs during spontaneous breathing. In preparation.

Jordanoglou, J, and Pride, N B (1968a). Factors determining maximum inspiratory flow and maximum expiratory flow of the lung. Thorax, 23, 33-37.

Jordanoglou, J, and Pride, N B (1968b). A comparison of maximum inspiratory and expiratory flow in health and in lung disease. Thorax, 23, 38-45.

Knudson, R J, Mead, J, Goldman, M D, Schwaber, J R, and Wohl, M E (1973). The failure of indirect indices of lung elastic recoil. American Review of Respiratory Disease, 107, 70-82.

Lowell, F C, and Schiller, I W (1953). Significance of changes in the expiratory rate observed during a measurement of the vital capacity in asthma. Journal of Allergy, 24, 492-498.

Mansell, A, Bryan, C, and Levison, H (1972). Airway closure in children. Journal of Applied Physiology, 33, 711-714.

Mead, J, Turner, J M, Macklem, P T, and Little, J B (1967). Significance of the relationship between lung recoil and maximum expiratory flow. Journal of Applied Physiology, 22, 95-108.

Medical Research Council Committee on the Aetiology of Chronic Bronchitis (1965). Definition and classification of chronic bronchitis for clinical and epidemiological purposes. Lancet, 1, 775-779. 
National Heart and Lung Institute (1974). Workshop on screening programs for early diagnosis of airway obstruction. American Review of Respiratory Disease, 109, 567-571.

Neuburger, N, Levison, H, Bryan, A C, and Kruger, K (1976a). Transit time analysis of the forced expiratory spirogram in growth. Journal of Applied Physiology, 40, 329-332.

Neuburger, N, Levison, H, and Kruger, K (1976b). Transit time analysis of the forced expiratory vital capacity in cystic fibrosis. American Review of Respiratory Disease, 114, 753-759.

Sartorelli, E (1966). Assessment of lung function in pneumoconiosis. In Respiratory Function Tests in Pneumoconiosis, p 27. International Labour Office, Geneva.

Smith, A A, and Gaensler, E A (1975). Timing of the forced expiratory volume in one second. American Review of Respiratory Disease, 112, 882-885.
Sykes, M K, McNicol, M W, and Campbell, E J M (1969). Respiratory Failure, pp 14-15. Blackwell, Oxford and Edinburgh.

Takishima, T, Grimby, G, Graham, W, Knudson, R, Macklem, P T, and Mead, J (1967). Flow-volume curves during quiet breathing, maximum voluntary ventilation and forced vital capacities in patients with obstructive lung disease. Scandinavian Journal of Respiratory Disease, 48, 384-393.

Yamabayashi, H, Takahashi, T, Tonomura, S, and Takahashi, H (1970). An analog model of the mechanical properties of lung and airway. In Airway Dynamics, edited by A Bouhuys, pp 33-42. Thomas, Springfield.

Requests for reprints to: Dr J Jordanoglou, Professorial Medical Unit, Evangelismos Hospital, Athens. 